\title{
DISCLAIMER
}

This report was prepared as an account of work sponsored by an agency of the United States Government. Neither the United States Government nor any agency thereof, nor any of their employees, makes any warranty, express or implied, or assumes any legal liability or responsibility for the accuracy, completeness, or usefulness of any information, apparatus, product, or process disclosed, or represents that its use would not infringe privately owned rights. Reference herein to any specific commercial product, process, or service by trade name, trademark, manufacturer, or otherwise does not necessarily constitute or imply its endorsement, recommendation, or favoring by the United States Government or any agency thereof. The views and opinions of authors expressed herein do not necessarily state or reflect those of the United States Government or any agency thereof.

$\mathrm{DOE} / \mathrm{ER} / 13792--5$

DE92 008743

\section{SPECTROSCOPY AND REACTION DYNAMICS \\ OF COLLISION COMPLEXES CONTAINING HYDROXYL RADICALS}

\author{
Progress Report
}

for Period June 1, 1991 - May 31, 1992

submitted by

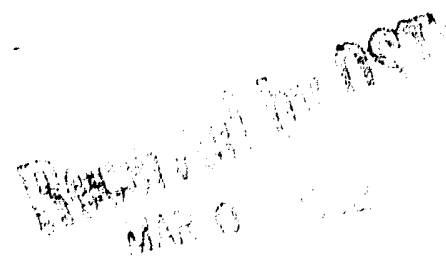

Marsha I. Lester

Department of Chemistry

University of Pennsylvania

Philadelphia, PA 19104-6323

February 1992

Prepared for

THE U. S. DEPARTMENT OF ENERGY

AGREEMENT NO. DE-FG02-87ER1379:.

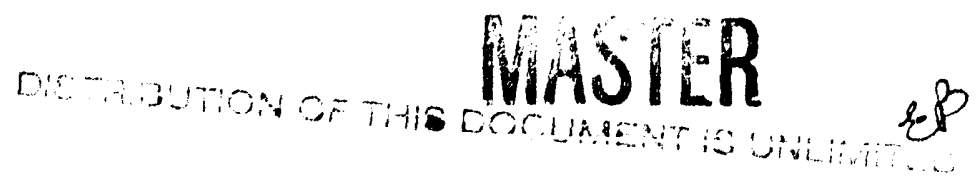


DOE PROGRESS REPORT,

$1991-92$

\section{$\underline{\text { Abstract }}$}

The internolecular bending and stretching vibrations supported by the $\mathrm{OH}\left(\mathrm{X}^{2} \Pi\right)+$ Ar $\left({ }^{1} S_{0}\right)$ potential energy surfaces have been accessed by stimulated emission pumping (SEP) of the weakly bound $\mathrm{OH}-\mathrm{Ar}\left(\mathrm{X}^{2} \Pi\right)$ complex. Virtually all of the bound vibrational levels of the complex, from the zero-point level to the dissociation limit, have been identified. Since these vibrations sample a wide range of orientations and distances on the intermolecular potential energy surface, this data can now be used to derive a global potential energy surface for the $\mathrm{OH}\left(\mathrm{X}^{2} \Pi\right)+\operatorname{Ar}\left({ }^{1} \mathrm{~S}_{0}\right)$ system. The first dissociation limit, producing $\mathrm{OH}\left(\mathrm{X}^{2} \Pi_{3 / 2}\right) \mathrm{v}=0, \mathrm{j}=3 / 2+\operatorname{Ar}\left({ }^{1} \mathrm{~S}_{0}\right)$ fragments, occurs between 93 and $103 \mathrm{~cm}^{-1}$ above the zero-point level as determined by the onset of bound-free features in the SEP spectra. In addition, metastable levels have been detected which lie as much as $200 \mathrm{~cm}^{-1}$ above the first dissociation limit. $\mathrm{OH}-\mathrm{Ar}$ complexes prepared in these levels undergo predissociation by using $\mathrm{OH}$ rotational or spin-orbit excitation to break the weak $\mathrm{OH}$-Ar intermolecular bond. Perturbation theory calculations have been carried out to understand the physical origin of the dynamical processes occurring on the $\mathrm{OH}\left(\mathrm{X}^{2} \Pi\right)+\operatorname{Ar}\left({ }^{1} \mathrm{~S}_{0}\right)$ potential energy surfaces.

The experiments performed in this laboratory under DOE support aim to provide a detailed picture of the intermolecular potential between the open-shell hydroxyl radical and various collision partners. To date, our work has focused on the spectroscopic characterization of the interaction potential between the open-shell hydroxyl radical and an argon atom, and on the collision dynamics taking place on these potential energy surfaces [1-9]. These studies revealed an enormous change in the potential upon electronic excitation of the $\mathrm{OH}$ moiety: the binding er argy of $\mathrm{Ar}$ to $\mathrm{OH}$ increases by nearly an order of magnitude, from approximate values of 90 to $740 \mathrm{~cm}^{-1}$, and the $\mathrm{OH}$ (center-of-mass) to $\mathrm{Ar}$ separation distance decreases by $0.7 \AA$. The dramatic change - in the potential is also manifested in the reaction dynamics: the rate of dissociation of the complex following vibrational excitation of $\mathrm{OH}$ occurs at least 10,000 times faster in the excited electronic state.

In the past year, we have implemented a new technique, stimulated emission pumping (SEP), to access the intermolecular stretching and bending vibrations supported by the $\mathrm{OH}\left(\mathrm{X}^{2} \Pi\right)+\mathrm{Ar}$ potentials [6-8]. Using theoretical calculations as a guide in understanding the energy level pattern $[10,11]$, we have assigned the SEP spectrum. The lowest four levels are a manifold of bending levels $\left(v_{b}=0-3\right)$ derived from the lowest rotational level of $\mathrm{OH}(j=3 / 2, \omega=3 / 2)$. These bends have average configurations ranging from the linear $\mathrm{O}-\mathrm{H}-\mathrm{Ar}$ (lowest energy state), through strongly bent, to linear $\mathrm{H}-\mathrm{O}-\mathrm{Ar}$. The energy spread across the manifold of bending levels reflects the anisotropy of the intermolecular potential. The small splitting of the $v_{b}=2$ and $v_{b}=3$ levels shows the weak angular dependence of the potential in the region about the $\mathrm{H}-\mathrm{O}$-Ar orientation. At higher energies, the bending level pattern is repeated with one, two, and three quanta of intermolecular stretching excitation. The energy spread across the bending levels decreases with intermolecular stretching excitation, showing that the intermolecular potential becomes more isotropic as the average $\mathrm{OH}$ - $\mathrm{Ar}$ separation distance is increased. Another group of bending levels has been identified near $96 \mathrm{~cm}^{-1}$, correlating to the rotationally excited $j=5 / 2, \quad \omega=3 / 2$ level of $\mathrm{OH}$. The first dissociation limit of $\mathrm{OH}-\mathrm{Ar} \longrightarrow \mathrm{OH}\left({ }^{2} \Pi_{3 / 2}\right) \quad v=0, j=3 / 2+\operatorname{Ar}\left({ }^{1} S_{0}\right)$ occurs within this manifold of bending levels. Using the lower limit $D_{0} \geq 93 \mathrm{~cm}^{-1}$ previously established by electronic 
spectroscopy [5], we can now bracket the first dissociation limit between 93 and $103 \mathrm{~cm}^{-1}$ above the lowest $\mathrm{OH}$-Ar level. A global potential energy surface for the $\mathrm{OH}\left(\mathrm{X}^{2} \Pi\right)+\mathrm{Ar}$ system is currently being derived based on the experimentally observed intermolecular vibrational energy levels from $0-89 \mathrm{~cm}^{-1}$.

Using SEP, we have also accessed many predissociative resonances which lie as much as $200 \mathrm{~cm}^{-1}$ beyond the first dissocation limit [6,8]. OH-Ar complexes prepared in bending levels correlating with $j=5 / 2, \omega=3 / 2$ or higher rotational levels of $\mathrm{OH}$, may predissociate by using $\mathrm{OH}$ rotational excitation to break the $\mathrm{OH}-\mathrm{Ar}$ intermolecular bond. All of the OH-Ar levels which correlate with the spin-orbit excited state of $\mathrm{OH}^{2} \Pi_{1 / 2}$ $(\omega=1 / 2)$ lie above the first dissociation limit. Complexes prepared in $\omega=1 / 2$ states may predissociate via spin-orbit relaxation. Perturbation theory calculations have revealed the couplings responsible for these dynamical processes [7]. The rates of rotational and spin-orbit predissociation provide information on off-diagonal (anisotropic) termis in the interaction potential and the difference potential, respectively. The latter is the change in the intermolecular potential when the odd electron in the free radical lies in or out of the O-H-Ar plane. Perturbation theory calculations were also used to understand the large parity splitting in certain vibrational bands. The measured parity splitting was used to infer the magnitude of the difference potential $\left(-12 \mathrm{~cm}^{-1}\right)$ in the region sampled by the first excited bend.

In the course of performing the SEP experiments, we discovered new information about the intermolecular vibrational levels supported by the electronically excited $\mathrm{OH}\left(\mathrm{A}^{2 \Sigma^{+}}\right) \mathrm{v}=0+\mathrm{Ar}$ potential energy surface. We have recently idertified the intermolecular bending vibration $\left(v_{b}{ }^{\prime}=1, v_{s}{ }^{\prime}=0\right.$ or $\Pi$-bend), without stretching excitation, and the intermolecular bends with two quanta of excitation $\left(v_{b}{ }^{\prime}=2, v_{s}{ }^{\prime}=0\right)$, denoted as the $\Sigma$ and $\Delta$ bends [9]. Previous bound state calculations based on an ab initio potential energy surface [12] predicted an extremely high frequency bending vibration of $-387 \mathrm{~cm}^{-1}$ $\left(v_{b}{ }^{\prime}=1, v_{s}^{\prime}=0\right)$. In contrast, Bowman and coworkers [13] had deduced a bending vibrational frequency of $280.5 \mathrm{~cm}^{-1}$ based on their assignrnent of bend-stretch combination bands in the high energy region of the fluorescence excitation spectrum (features denoted as $A$, $-B$, and $C$ in Ref. 5 were assigned as $\left.v_{b}{ }^{\prime}=1, v_{s}{ }^{\prime}=3-5\right)$. Our observation of the fundamental bending vibration conclusively demonstrates that the $\mathrm{OH}\left(\mathrm{A}^{2} \Sigma^{+}\right)+\mathrm{Ar}$ potential in the region of the O-H-Ar attractive well is les's anisotropic than predicted by the $a b$ initio calculation [14]. Theoretical calculations are being performed in collaboration with $D$. C. Clary (Cambridge) to derive the $\mathrm{OH}\left(\mathrm{A}^{2 \Sigma^{+}}\right)+$Ar potential energy surface based on our new experimental data.

In the past year, the personnel on this project have changed. Dr. Mary T. Berry, a postdoctoral associate, has become an Assistant Professor of Chemistry at the University of South Dakota. Mitchell R. Brustein obtained Ph.D. in 1991 based on this project with a thesis entitled "Spectroscopy and Dynamics of the OH-Ar van der Waals Complex." He is currently a postdoctoral associate at the University of Montreal. Two new graduate students are now working on this project: Richard A. Loomis, a third year student, and Leanna C. Giancarlo, a second year student.

The principal investigator, Marsha I. Lester, has devoted approximately $33 \%$ of her effort towards this project in the current term and expects to devote the same effort for the duration of the project. 


\section{REFERENCES}

1. M. T. Berry, M. R. Brustein, J. R. Adamo, and M. I. Lester, J. Phys. Chem. 92, 5551 (1988).

2. M. T. Berry, M. R. Brustein, and M. I. Lester, Chem. Phys. Lett. 153, 17 (1988).

3. M. T. Berry, M. R. Brustein, and M. I. Lester, J. Chem. Phys. 91, 5878 (1989).

4. K. M. Beck, M. T. Berry, M. R. Brustein, and M. I. Lester, Chem. Phys. Lett. 162, $203(1980)$

5. M. T. Berry, M. R. Brustein, and M. I. Lester, J. Chem. Phys. 92, 6469 (1990).

6. M. T. Berry, M. R. Brustein, M. I. Lester, C. Chakravarty, and D. C. Clary, Chem. Phys. Lett. 178, 301 (1991).

7. W. H. Green, Jr. and M. I. Lester, J. Chem. Phys., in press.

8. M. T. Berry, R. A. Loomis, L. C. Giancarlo, and M. I. Lester, J. Chem. Phys., in press.

9. R. A. Loomis, L. C. Giancarlo, M. T. Burry, M. I. Lester, and D. C. Clary, maruscript in preparation.

10. C. Chakravarty and D. C. Clary, J. Chem. Phys. 94, 4149 (1991).

11. M.-L. Dubernet, D. Flower, and J. M. Hutson, J. Chem. Phys. 94, 7602 (1991).

12. C. Chakravarty and D. C. Clary, J. Chem. Phys. 93, 3367 (1990).

- 13. J. M. Bowman, B. Gazdy, P. Schafer, and M. C. Heaven, J. Phys. Chem. 94, 2226 (1990).

14. A. Degli Esposti and H.-J. Werne;, J. Chem. Phys. 93, 3351 (1990). 
DOE Supported Publications, 1991 - 92

1. M. T. Berry, M. R. Brustein, M. I. Lester, C. Chakravarty, and D. C. Clary, "Stimulated Emission Pumping of van der Waals Vibrations in the Ground Electronic State of OH-Ar", Chem. Phys. Lett. 178, 301 (1991).

2. W. H. Green, Jr. and M. I. Lester, "A Perturbation Theory Guide to Open-Shell Complexes: $\mathrm{OH}-\operatorname{Ar}\left(\mathrm{X}^{2} \Pi\right) "$, J. Chem. Phys., in press.

3. M. T. Berry, R. A. Loomis, L. C. Giancarlo, and M. I. Lester, "Stimulated Emission Pumping of Intermolecular Vibrations in $\mathrm{OH}-\mathrm{Ar}\left(\mathrm{X}^{2} \Pi\right) ", J$. Chem. Phys., in press.

4. R. A. Loomis, L. C. Giancarlo, M. T. Berry, M. I. Lester, and D. C. Clary, "Experimental Determination of the Intermolecular Bending Potential in $\mathrm{OH}-\operatorname{Ar}\left({ }^{2} \Sigma^{+}\right) "$, manuscript in preparation. 

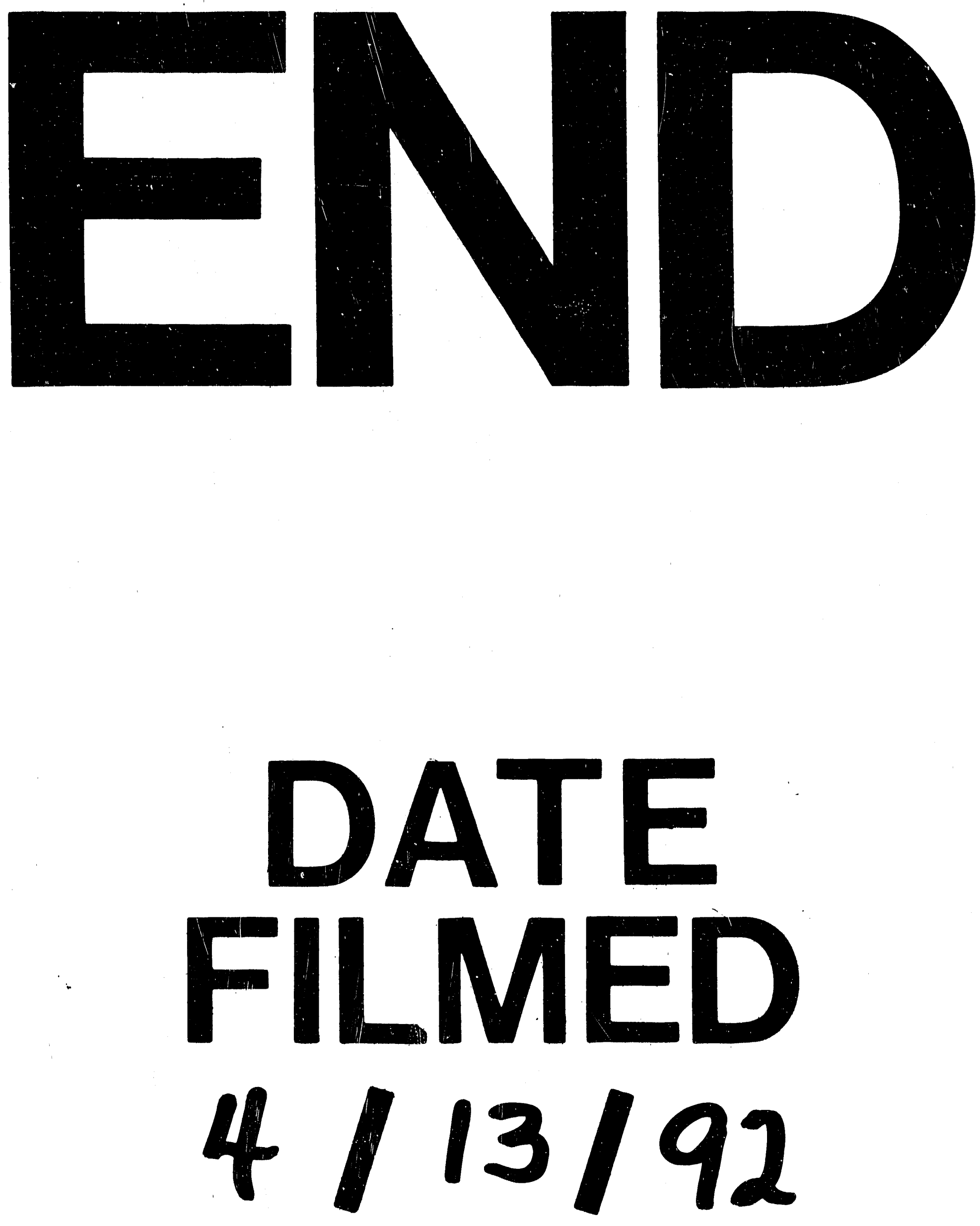

I 
